\title{
Application of Focus Ion Beam Technique for TEM Multilayer Materials Examination
}

\author{
J. Wojewoda-Budka,* P. Zięba,* J. Morgiel,* N. Sobczak,** R. Nowak** \\ *Institute of Metallurgy and Materials Science, Polish Academy of Sciences, 25 Reymonta Street, \\ 30-059 Cracow, Poland \\ **Foundry Research Institute, 73 Zakopianska Street, 30-418 Cracow, Poland
}

Focus Ion Beam (FIB) preparation technique was originally designed for the electronic industry purposes. Therefore, materials other than silica could be a challenge to prepare - especially multilayer samples with different hardness, rendering amorphous, gallium implantation etc. In spite of these problems undoubtedly such advantages as: imaging sample during preparation (thin foil from the desired location), reduced preparation time, optimized sample thickness, predominate.

The paper presents the potential of FIB technique based at two examples. The first one is the joint dedicated for electronic industry especially for the high power semiconductor components manufactured using diffusion soldering technology [1-3]. In this case FIB allowed to reveal microstructural and microchemical features of the intermetallic phases formed due to soldering of copper with indium-bismuth alloy. The second case refers to so called Co-Continuous Ceramic Composites (C4). In situ reaction of the molten aluminum with yttria $\left(\mathrm{Y}_{2} \mathrm{O}_{3}\right)$ or zinc oxide $(\mathrm{ZnO})$ substrates led to formation of the so-called reaction product region (RPR). In order to follow the sequence of reactions it was necessary to observe the microstructure and perform the phase identification in particular places. Quanta 3D (FEI) equipped in Omniprobe micromanipulator let to prepare the thin foils for transmission electron microscopy (TEM) investigations for all new-formed phases and their interfaces.

The diffusion soldering technology allows to produce thermally stable joints dedicated to the electronic equipment thanks to controllable growth of intermetallic phase(s). Detailed microstructural examination of the intermetallics is essential when such process is involved. The annealing of the $\mathrm{Cu} / \mathrm{In}-22 \mathrm{at} . \% \mathrm{Bi} / \mathrm{Cu}$ joints in the temperature range of $85-150{ }^{\circ} \mathrm{C}$ resulted in $\Theta\left[\mathrm{Cu}_{11} \mathrm{In}_{9}\right]$ phase formation. Transmission electron microscopy studies showed transformation of $\Theta$ phase enriched in $\mathrm{Bi}$ into $\eta\left[\mathrm{Cu}_{2} \mathrm{In}\right]$ phase. In the temperature range of $300-325{ }^{\circ} \mathrm{C}$ the $\eta$ grew in the form of homogeneous layer at the $\mathrm{Cu} / \mathrm{In}-\mathrm{Bi}$ solder interface and at $350{ }^{\circ} \mathrm{C}$ and higher as the peninsulas of islands surrounded by unreacted solder. The third high-melting intermetallic phase $\delta\left[\mathrm{Cu}_{7} \mathrm{In}_{3}\right]$ coexisted with $\eta$ at $350{ }^{\circ} \mathrm{C}$. TEM investigation of the $\delta /$ copper substrate interface showed the formation of solid solution of In and $\mathrm{Bi}$ in $\mathrm{Cu}$.

The Co-Continuous Ceramic Composites were produced due to contact heating at $1000{ }^{\circ} \mathrm{C}$ of aluminum and yttria $\left(\mathrm{Y}_{2} \mathrm{O}_{3}\right)$. Wavy shaped reaction product region (RPR) $\sim 1 \mathrm{~mm}$ was consisted of three zones and extended into the oxide substrate. The first RPR zone close to the aluminum drop was found to be the fine crystalline $\mathrm{Al}_{5} \mathrm{Y}_{3} \mathrm{O}_{12}$ (YAG) precipitates interspersed in the $\mathrm{Al}_{3} \mathrm{Y}$ matrix. Larger $\mathrm{AlYO}_{3}$ (YAP) crystals were within the second zone while the third one presented the microstructure characteristic for the interpenetrating $\mathrm{C} 4$ composites. The elongated YAP precipitates (oxide) were interspersed in the $\mathrm{Al}_{2} \mathrm{Y}$ phase. Other subject of studies within the $\mathrm{C} 4$ group was the product of the interaction between liquid $\mathrm{Al}$ and $\mathrm{ZnO}$. It was affected by the strong evaporation of reactively formed zinc. As a consequence, it contributed to the enhanced transport of $\mathrm{Al}$ and $\mathrm{Zn}$ to and from the reaction front, respectively, resulting in creating favorite conditions for the redox reaction. The structural observations confirmed the formation of the reaction product region of $\sim 50$ 
$\mu \mathrm{m}$ of thickness extending into the $\mathrm{ZnO}$ substrate. The RPR structure corresponded to the $\mathrm{C} 4$ type since it was composed of ceramic $\mathrm{Al}_{2} \mathrm{O}_{3}$ and metallic $\mathrm{Al}(\mathrm{Zn})$ mutually interpenetrating networks. Further examination revealed that the $\alpha-\mathrm{Al}_{2} \mathrm{O}_{3}$ type was the main component of the RPR layer. Moreover, the thin columnar $\delta-\mathrm{Al}_{2} \mathrm{O}_{3}$ layer next to the $\mathrm{ZnO}$ substrate was also observed. Most probably, this low-temperature modification of aluminum oxide was formed during cooling of the $\mathrm{Al} / \mathrm{ZnO}$ couple.

\section{References}

[1] G. Humpsten et al., Principles of soldering and brazing, ASM International, Materials Park, $\mathrm{OH}$, 1993.

[2] D.M Jacobson et al., Novel applications of diffusion soldering, GEC-Marconi Materials Technology Ltd, Hirst Division, Hertfordshire, 1995.

[3] P.K. Khanna, S.K. Bhatnagar, G. Dalke, D. Brunner, W. Gust, Mater. Sci. Eng. B33 (1995), 16.

[4] D.R. Clarke, J. Am. Ceram. Soc. 75 (1992), 739.

[5] M.C. Breslin, J. Ringnalda, L. Xu, M. Fuler, J. Seeger, G.S. Daehn, T. Otani, H.L. Fraser, Mater. Sci. Eng. A195 (1995), 113.

[6] W. Liu, U. Koster, Scripta Mater 35 (1996), 35.

[7] N. Sobczak, Solid State Phenomena 101-102 (2005), 221.

[8] This work has been supported by the Ministry of Science and Higher Education in Poland under Project N N507 272836 and in the frame of grant for young researchers under the START programme of the Foundation for Polish Science.
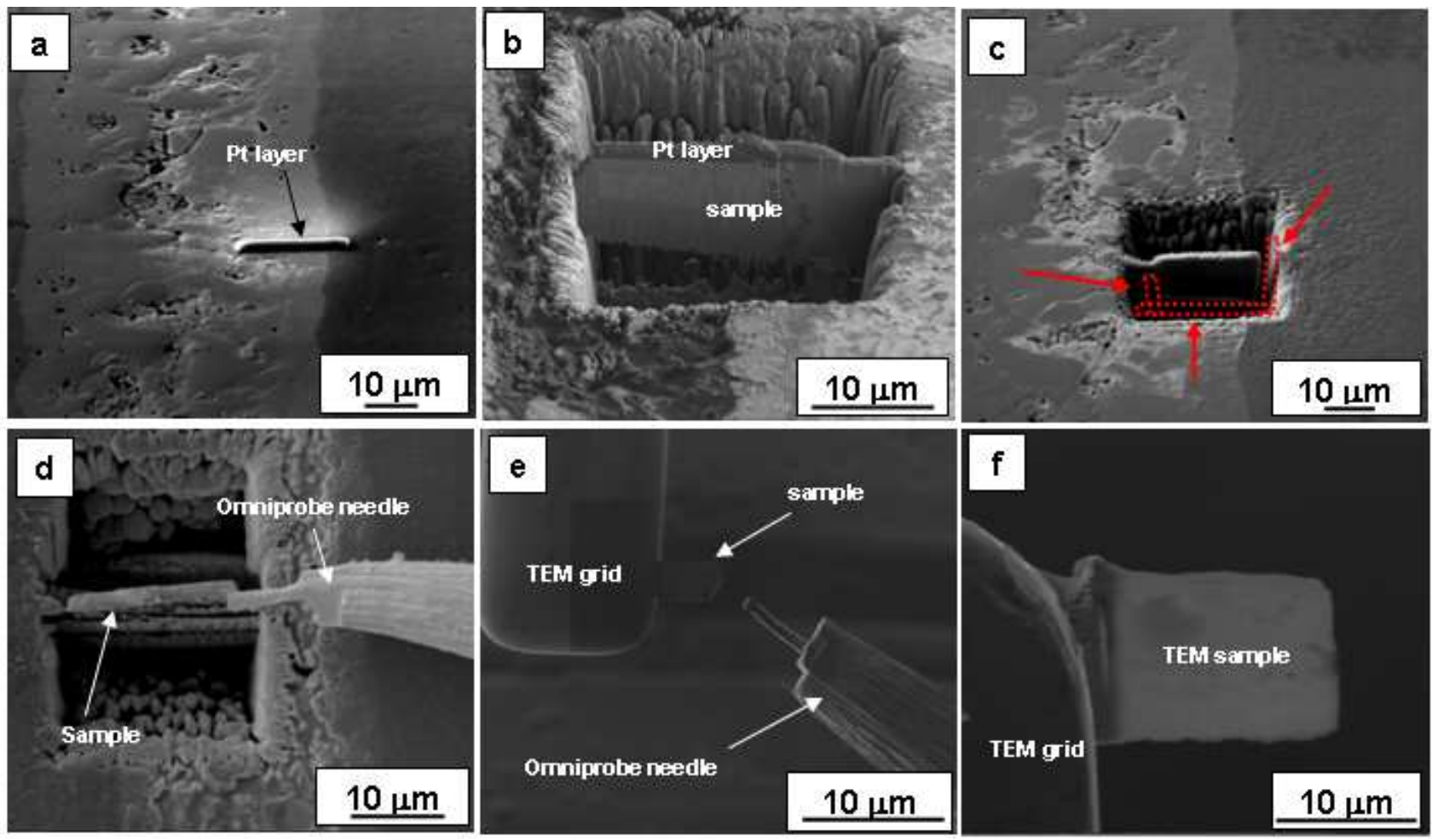

FIG. 1. Stages of in-situ FIB technique comprising deposition of the protective platinum layer (a), bulk milling of the material close to the area to be investigated (b), cutting out the lamella (c), in-situ foil extraction using micromanipulator in the chamber (d), welding of the lamella on a TEM grid (e) and final thinning of the TEM sample (f). 